\title{
Top10 inspectors: Board game for a meaningful preparation of standardized tests
}

Received: 23/02/2017

Accepted: 29/03/2017

DOI: https://doi.org/10.21897/25394185.1486

\author{
Top10 inspectors: juego de mesa para una preparación \\ significativa de pruebas estandarizadas
}

Kenneth Steenhuisen, kenneth.steenhuisen@marymountbq.edu.co

Marymount School, Barranquilla, Colombia

\section{Resumen}

Los exámenes estandarizados son una forma de evaluación formativa que permite a las instituciones obtener información para diferenciar y medir el proceso de aprendizaje de los estudiantes. Sin embargo, los docentes frecuentemente optan por preparar únicamente para el examen a través de una serie de simulacros, estrategias para pruebas estandarizadas y análisis de preguntas. TOP10 Inspectors es una innovación pedagógica en forma de juego de mesa que le permite al docente desarrollar habilidades comunicativas, trabajar procesos de pensamiento y fortalecer la motivación estudiantil hacía su propio aprendizaje. Este artículo explica cómo el juego está compuesto y los resultados obtenidos al preparar a los estudiantes para un examen de suficiencia en inglés.

Palabras claves: Motivación, Aprendizaje basado en tareas, habilidades de pensamiento y retroalimentación.

\section{Abstract}

Standardized tests are considered a formative assessment that provide schools with the data needed to differentiate and work effectively on the learning process of the students. However, teachers frequently opt for preparing explicitly for the test by having the students sitting several mock exams, giving tips, and analyzing questions. TOP10 Inspectors is a pedagogical innovation in the form of a board game that enables the teacher to develop communication skills, work Higher Order Thinking Skills (H.O.T.S), and increase the students' motivation for the their own learning process. This article explains how the game is set up and the results obtained when implementing it for the preparation of an English Proficiency Test.

Keywords: Motivation, Task Based Learning, HOTS, and feedback. 
Standardized testing has become a worldwide form of assessment adopted by many institutions that aim to have a reliable indicator of the learning process of their students. According to Meador (2016) standardized tests objectivity, not subjectivity, enables to determine if the student fully grasps the concepts they are learning and to make the appropriate comparisons ${ }^{1}$. Besides, Cambridge Educational Services indicate that standardized tests provide data that drive instructions and helps school close achievement gaps ${ }^{2}$. Therefore, the benefits of standardized testing have a visible impact on all the stakeholders in the educational system. On one side, students develop test-taking skills that will accompany them along their learning process. Teachers, also, collect plausible data that serve as objective indicators of students' performance. This data then allows differentiation, well-established formative assessment, and helps them provide meaningful feedback. On the other hand, schools can use the data to self-evaluate the quality of their teaching-learning processes compared to other schools. Based on these results, schools are ranked to provide parents with the information needed to make the right choice when selecting the school for their children, but also to accompany their learning process by giving support on the areas for improvement.

Nevertheless, standardized testing also has its drawbacks. Thomas Armstrong in ASCD (2013) indicated that «due to the emphasis placed on standardized test results these days, teachers are spending more and more time «teaching to the test.» Most of the classroom time consists of either taking the tests or preparing for the tests, and this shuts out the possibility of learning anything new or important ${ }^{3} \gg$ Therefore, given the importance of these results, the domino effect starts taking place. To start with, schools prioritize the preparation for this type of exam as a strategy to escalate in the ranking, consolidate its reputation, and increase their population and incomes. Consequently, teachers focus on preparing for an exam, teaching the content that will be evaluated in the test, rather than developing skills and competencies that are more beneficial on the short, medium, and long-term. It is then the student who feels the pressure to perform and obtain the results all the stakeholders expect. In conclusion, this snowball makes schools deviate from their main objective: provide students with the skills and competencies needed to succeed in life challenges.

The problem aggravates when it comes to the analysis of the resources for the preparation of standardized tests. Research has shown that the available material to prepare for this type of assessment can be easily summarized in mock tests, tips, booklets, question banks, and some videos from teachers who have taken the test and share their experiences. This means that there is no meaningful connection between the preparation and the students' real needs. The students are more than a digit located on a benchmark. Digits that, after a few months, will no longer be reliable when the students have forgotten the content studied for the standardized test at that moment.

In addition, another paramount aspect to analyze is the motivation students have when facing the preparation process for a standardized exam. Important elements as 21 st-century skills, critical thinking, opinion exchange, case solving, real-world connections, communication, and students' agency are unavoidable if the school wants an effective learning process. Dornyei (2001) emphasizes on the importance of presenting engaging tasks that motivate learners and have a significant impact on their students ${ }^{4}$. Thus, schools cannot prevail the standardized tests above the skills and competencies that need to be developed. In fact, they should rather design and adapt the material to bring meaningfulness to the learning process. 


\section{Designing Material}

As the name indicates, standardized tests are based on a standardized measurement so students' results can be interpreted on a scale. To be effective in the preparation process, the content of the test needs to be analyzed in depth. This study will be vital to perform a needs analysis in the class so the teacher is able to identify the students' strengths and areas for improvements.

Once the analysis has been completed, then it is time to design and adapt material for the preparation. The implementation of mock tests, reading exam tips, and solving questions together is part of the process, but the risk of over testing is huge and the consequences can stagnate the learning process. Hence, teachers need to be creative, adapt and design material to help students get engaged, and make connections to be well prepared for any challenge they may face.

\section{Top10 Inspectors: A Pedagogical Innovation}

A few years ago, as the bilingual coordinator in a private school in Barranquilla, Colombia, I had the challenge of preparing the students from different grades for a variety of standardized tests. The students from 5th and 9th grade were about to sit two official language proficiency tests from Cambridge Language Assessment called Key English Test (K.E.T.) and Preliminary English Test (P.E.T.). The students from 3rd, 5th, and 9th grade were going to take the Pruebas Saber 3, 5, 9 and the seniors had to get prepared, as every school in the country, for the state exam called Pruebas Saber 11.

Even though the material available was relevant, it was not appealing to the students. Their lack of motivation led to no commitment that would not only lead to poor results that would also not reflect the students' real competencies.

As a consequence, the preparation material needed to be adapted and new strategies needed to be designed to engage the students. This is the moment when TOP10 Inspectors was created as a formative assessment that could break the routine, motivate the students, get them to participate, so positive feedback could be given to the students and a more effective support could be offered to them.

When it comes to motivation, games are very successful as it enables students' participation.

Besides, competitiveness also helps attract their attention to keep them focus on something. So, I decided to create a board game that my students could play in class.

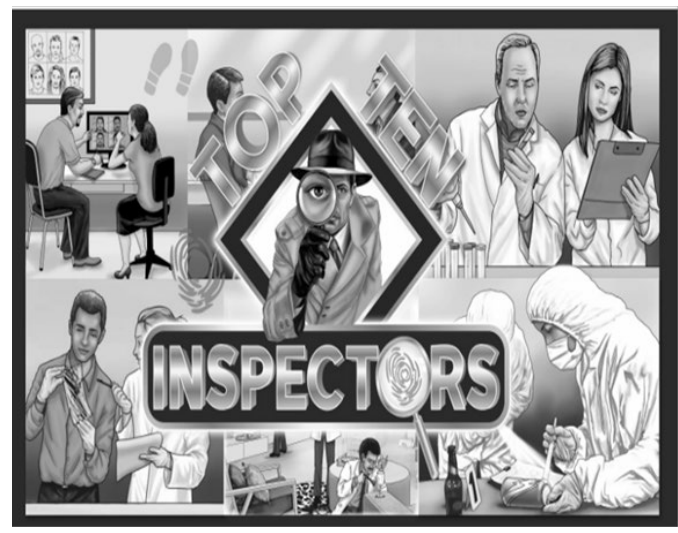

Figure 1. Top10 Inspectors box

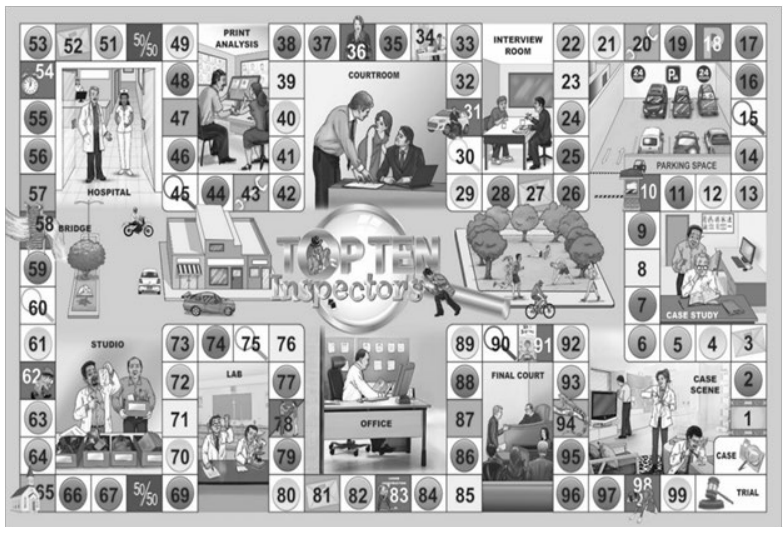

Figure 2. Top10 Inspectors board game 
The next step was to connect the game with the content of the exam. This is the key part of the game since it enables the teacher to present the exam content through a very creative and engaging game. Thus, the board game was designed with boxes that corresponded to six different categories. Each category was a type of question from the exam. In the case of the Language Proficiency Exams, the six categories are Reading Comprehension, Speaking, Grammar, Vocabulary, Pronunciation, and Culture. In case of the Pruebas Saber, the six categories corresponded to subjects: Spanish, English, Physics, Biology/Chemistry, Math, and History. Depending on the color of the box, the player would get a question from that category. Each correct answer awards 5 points.

Having made the connection between the game and the exam, it was time to include higher-order thinking skills and make it interesting to the students. With this in mind, the methodology of the game was established. The main goal was to release students from the pressure of being constantly observed and assessed in order to get more actively prepared for the exam.

In TOP10 INSPECTORS, the students get the role of inspectors and it is recommended to be played in 5 groups; each group of 3,4 or even 5 students depending on the number of students in the class. First of all, the roles must be assigned. There is a Master Inspector (M.I.), the teacher, who guides the game by asking questions and giving points to the groups. The M.I. also groups the students keeping a balance among them in terms of language proficiency and peer support.

The players will have some aids and threats along the game. The blue boxes are the aids that will help them solve some drawbacks caused by the threats.

\section{Developing H.0.T.S.}

Another important element of the game is the immense need to develop Higher- Order Thinking Skills (HOTS) in the students. To do so, after the groups have been established, the M.I. starts the game by reading the case aloud to all the groups while the inspectors (the students) take note of the most relevant information. In this part of the game, the students work on listening, also build memory in a foreign language in order to summarize the information, identify the main idea and essential details of a piece of information. These are important factors that improve their communication skills.

\section{How to win}

There are two ways of claiming victory. One is by answering all the questions until the group gets to the Trial (box 100). This motivates the students to answer the questions correctly and gather as many points as possible. The other possible way is to gather 50 points and solve the case, but the inspectors must be careful as they may lose all points if they do not give the right answer. This second option helps to keep all the students motivated even when they are far behind in the game. In other words, the winner will not always be the group leading the game but, at any moment of the game, another group can gather the 50 points, solve the case, and beat their opponents.

\section{Amount of time needed}

The duration of this game is approximately 3 hours, but it can vary depending on the complexity of the questions, the students' proficiency level and the way the Master Inspector (M.I.) manages the time. This refers to the fact that the M.I. guides the game, so he can then stop it as many times as he considers necessary to provide feedback and explain something important to the whole group. However, it is recommended to keep in mind that it is a game which means that it cannot lose its sequence and fluency to keep the players engaged. Additionally, the M.I. must make sure it does not become a traditional lesson as it would affect the students' interest and motivation. 


\section{Task-Based learning}

Research is paramount to define the structure of the game too. That is the reason why Task-Based Learning (TBL) was included in the design. These are Collaboration, Critical Thinking, Case Solving, Decision Making, and Opinion Exchange. By comparing the principles of TBL to the board game as a tool to assess the students' improvement, the following analysis is presented:

Table 1. Comparison between TOP10 INSPECTORS and TBL

\begin{tabular}{ll}
\hline \multicolumn{1}{c}{ Task-Based Learning } & \multicolumn{1}{c}{ Top10 Inspectors } \\
\hline Collaborative Task & Students play in groups \\
& Riddles, multiple tasks, students listen to a case and \\
Thinking As A Core Of The Task & take notes of the main idea \\
Case Solving & There is a case and some clues to solve it. \\
Decision Making & There is captain who makes the final decision. \\
Opinion Exchange & Students discuss in group the answer to the questions. \\
\hline
\end{tabular}

\section{Developing skills}

Owing to the fact that the main objective of the research was meaningful learning and the development of the four macro skills through the implementation of TBL and TOP10 INSPECTORS, it was necessary to define how each skill was going to be reinforced. On one side, it was complicated to work listening through an audio or recording and, on the other side, the game had to be active so inspectors would not have enough time to be writing down long answers. As a consequence, the following chart shows how each skill was improved through the game:

Table 2. Developing integrated skills through TOP10 ISNPECTORS

\begin{tabular}{ll}
\hline \multicolumn{1}{c}{ Skill } & \multicolumn{1}{c}{ Top10 Inspector } \\
\hline Reading & Questions from the game that were based on the KET format. Students had to \\
& read short paragraph and answer a question in less than a minute. \\
Speaking & Through questions from the game and tasks such as: TEAMWORK: Choose \\
& a speaking question. One inspector (student) will give an oral answer and his \\
& teammate will write it down correctly. If both answers are correct, you will get \\
& 10 points. The game is played in the target language and if an inspector uses \\
& a different language than the target language, the group will lose 5 points. So, \\
& every discussion, question, answer, feedback is given in English. \\
& Reinforced through the improvement of the pronunciation of the students and the \\
Listening & extension of their vocabulary. They also listen to a case and build memory in a \\
foreign language. It covers the vocabulary needed in an A2 English level. \\
Improved through grammar questions and A2 vocabulary. \\
The students take note of a case they listen to. \\
There is a task that includes writing an answer and is checked by the M.I. \\
\hline
\end{tabular}




\section{Case Study - Playing Top10 Inspectors}

Once TOP10INSPECTORS had been designed, the next step was to put the new tool into practice to assess its effectiveness based on the students' improvement. 15 students from 5th grade (10 to 12 years old) were going to play the game as a strategy to prepare them for the K.E.T. exam. I first did a Needs Analysis through observation where I identified that they had mixed proficiency levels and used to answer back in Spanish rather than in the target language, even though they had the language proficiency to reply in English.

Additionally, the previous process that this group was having in terms of preparation for the KET exam was completely focused on the exam rather than on language acquisition. The entire lesson was based on studying the exam, correcting mistakes and developing several strategies to answer the questions properly.

The following chart compares the methodology used prior to the introduction of the game:

Table 3. Strategies implemented to reinforce the macro skills

\begin{tabular}{lll}
\hline \multicolumn{1}{c}{ Description } & \multicolumn{1}{c}{ Traditional Process } & \multicolumn{1}{c}{ Research Process } \\
\hline Reading & Scanning, Skimming, predicting, & TOP10INSPECTORS \\
& word from context, etc. & \\
Writing & Spelling, grammar & TOP10INSPECTORS \\
Speaking & Pronunciation, questions. & TOP10INSPECTORS \\
Listening & Vocabulary, predicting. & TOP10INSPECTORS \\
\hline
\end{tabular}

The students took 3 periods of class to play the game. Due to the excitement it caused, the students wanted to play it several times. Since the game comes with 5 different cases and 45 questions in each category, it was possible to play the game 3 times. The only change made was the case.

\section{Results}

The implementation of TOP10 Inspectors inside the classroom brought some enormous changes with great results in the students. These results were:

TBL changed the classroom environment and helped to create more interest from the students' side towards the exam.

It also enabled the integration of the four macro skills needed to be developed, since the students did not receive a specific section for each skill but were using all of them in each task presented.

The teacher talking time was significantly reduced while the students talking time was increased as the lesson became student-centered and they were engaged playing the game.

TBL also allows the material to be adapted to the real students' needs and that means that there was scaffolding in the lesson based on the student's progress during the game.

The students were always communicating in the target language, something difficult to achieve in a traditional class where the students' production is limited.

The use of a board game as TOP10 INSPECTOR as a tool for formative assessment also helped to create authentic opportunities to analyze each student in a more natural context.

The students felt part of the learning process, they realized the importance of developing communication skills beyond the standardized test.

The students were focused on the game, enjoyed playing it, and considered every question not as an exam but as a challenge to move forward in the game. 
The students were highly motivated in the lesson, showed great interest to learn, corrected their mistakes, and understood why an answer was wrong. It was in here where the feedback played an important role as every student was paying attention since they considered it was important information that would help them to win.

The students also worked on their critical thinking through group discussions to solve the case presented. This helped them in terms of cognition and analysis of information, which will be of great help when presenting the exam.

At the end, the students were impressed by their own results as they realized they had been able to understand the instructions, the case, answered the questions, and produce in the target language for three hours. This showed them that they were capable of overcoming the fear of getting prepared for a test. This increased their motivation and self-confidence in the process.

Additionally, by comparing the results obtained before the implementation of TOP10 INSPECTORS and the ones achieved with the game, these are the outcomes.

Table 4. reflections based on observation of the strategies applied

\begin{tabular}{|c|c|c|c|}
\hline Aspect & $\begin{array}{l}\text { Traditional Process Before } \\
\text { The Game }\end{array}$ & Research Process & Results \\
\hline Oral Production & $\begin{array}{l}\text { During the classes, the } \\
\text { students' production needed } \\
\text { to be increased. }\end{array}$ & $\begin{array}{l}\text { There was in a constant oral } \\
\text { production in group (Student- } \\
\text { Student interaction). The } \\
\text { teacher only asked the question } \\
\text { and had them working on the } \\
\text { answers. Teacher talking time } \\
\text { was minimal. }\end{array}$ & $\begin{array}{l}\text { By playing the game, there was in a } \\
\text { higher interaction (student-student, } \\
\text { teacher-student) that was not always } \\
\text { achieved in the traditional process. }\end{array}$ \\
\hline Confidence & $\begin{array}{l}\text { Students learnt how to answer } \\
\text { the questions of the exams in } \\
\text { less time. }\end{array}$ & $\begin{array}{l}\text { Students gained confidence } \\
\text { to produce the language and } \\
\text { make mistakes. Implicitly, } \\
\text { they were improving on the } \\
\text { different skills. }\end{array}$ & $\begin{array}{l}\text { The traditional process focused on } \\
\text { developing the different skills through } \\
\text { specific strategies. The research process } \\
\text { was more focused on oral production } \\
\text { rather than on a test. }\end{array}$ \\
\hline Strategies & $\begin{array}{l}\text { Developed specific strategies } \\
\text { for improving results at } \\
\text { certain skills }\end{array}$ & $\begin{array}{l}\text { The game did not explicitly } \\
\text { work on strategies, but helped } \\
\text { students improve by focusing } \\
\text { on the answer, discuss it in } \\
\text { group, share the answer, and } \\
\text { get the feedback from the } \\
\text { teacher. }\end{array}$ & $\begin{array}{l}\text { Both ways are effective when } \\
\text { reinforcing students' language skills. } \\
\text { Students must know what strategies } \\
\text { to apply during a test, but they also } \\
\text { need to lose the fear to make mistakes } \\
\text { and discover them to find the correct } \\
\text { answer. }\end{array}$ \\
\hline Grammar & $\begin{array}{l}\text { Grammar was taught } \\
\text { implicitly and connected with } \\
\text { the test. }\end{array}$ & $\begin{array}{l}\text { Grammar was taught } \\
\text { implicitly through questions } \\
\text { rather than explaining a topic. }\end{array}$ & $\begin{array}{l}\text { There is no need to teach grammar } \\
\text { explicitly. }\end{array}$ \\
\hline Motivation & $\begin{array}{l}\text { Students had an extrinsic } \\
\text { motivation since they wanted } \\
\text { to score good in the test. }\end{array}$ & $\begin{array}{l}\text { Students forgot the pressure of } \\
\text { the test and were motivated to } \\
\text { win the game. }\end{array}$ & $\begin{array}{l}\text { To prepare students for standardized } \\
\text { exams, teacher can use other strategies } \\
\text { that can bring more confidence to the } \\
\text { students. }\end{array}$ \\
\hline
\end{tabular}


Finally, the 15 students who participated in this research took the official test K.E.T. For the first time in the school from the 15 students, the results confirmed the analysis as 11 passed the test with the corresponding A2 level from the based on the Common European Framework of Reference; 3 passed it with merit, which corresponds to an A2+, and one student even passed it with distinction, which is a B1.

\section{Conclusion}

To sum up, standardized proficiency tests play an important role in our educational system as they function as an assessment strategy for the language proficiency of the students and the quality of the education in the country. It also presents results that do not only rank the school, but also provide the teacher with enough data to differentiate. However, teachers need to motivate the students and adapt the lessons in a way that connects the content of the exam with the real students' needs.

Regarding teaching strategies for each skill, it is important because it helps students to learn how to answer questions for a test in less time. However, the learning process of a foreign language goes beyond the "teaching to a test". In this case, the implementation of TOP10 INSPECTOR changed the learning environment notoriously, developed their communication skills and permitted the students to have a meaningful learning process while also scoring great results in the test.

\section{Notes}

${ }^{1}$ «Benefits of Standardized Testing for Students and Teachers.» 6 Oct. 2016, https://www.cambridgeed. com/BenefitsOfStandardizedTesting. Accessed 29 Apr. 2018.

2 «Cambridge Educational Services > News.» 6 Oct. 2016, https://www.cambridgeed.com/ BenefitsOfStandardizedTesting. Accessed 29 Apr. 2018.

3 (n.d.). ASCD EDge - 15 Reasons Why Standardized Tests are Problematic. Retrieved April 29, 2018, from http://edge.ascd.org/blogpost/15-reasons-why-standardized-tests-are-problematic

${ }^{4}$ (n.d.). The Importance of Motivation in Second Language ... - ARC Journals. Retrieved April 29, 2018, from https://www.arcjournals.org/pdfs/ijsell/v3-i2/12.pdf

\section{References}

«Benefits of Standardized Testing for Students and Teachers.» 6 Oct. 2016, https://www.cambridgeed. com/BenefitsOfStandardizedTesting. Accessed 29 Apr. 2018.

«Cambridge Educational Services > News.» 6 Oct. 2016, https://www.cambridgeed.com/ BenefitsOfStandardizedTesting. Accessed 29 Apr. 2018.

Armstrong, T. (n.d.). ASCD EDge - 15 Reasons Why Standardized Tests are Problematic. Retrieved April 29, 2018, from http://edge.ascd.org/blogpost/15-reasons-why-standardized-tests-areproblematic

«Cambridge Educational Services> News.» 6 Oct. 2016, https://www.cambridgeed.com/ BenefitsOfStandardizedTesting. Accessed 29 Apr. 2018.

Dornyei (2001) (n.d.). The Importance of Motivation in Second Language ... - ARC Journals. Retrieved April 29, 2018, from https://www.arcjournals.org/pdfs/ijsell/v3-i2/12.pdf

Meador (2016). «Benefits of Standardized Testing for Students and Teachers.» 6 Oct. 2016, https:// www.cambridgeed.com/BenefitsOfStandardizedTesting. Accessed 29 Apr. 2018. 